\begin{tabular}{|c|c|c|}
\hline 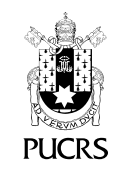 & $\begin{array}{l}\text { ESCOLA DE } \\
\text { HUMANIDADES }\end{array}$ & $\begin{array}{l}\text { Revista Digital do Programa de Pós-Graduação em Letras da PUCRS } \\
\text { Letrônica, Porto Alegre, v. 14, n. 2, p. 1-11, abr.-jun. } 2021 \\
\text { e-ISSN: } 1984-4301\end{array}$ \\
\hline de) $h$ ttp: //dx & $\mathrm{rg} / 10.15448 / 1984-4301.2021 .2 .38392$ & \\
\hline
\end{tabular}

SEÇÃO: ARTIGOS

\title{
Comportamento ocular durante a leitura e compreensão de uma questão de raciocínio lógico
}

\author{
Eye behavior during reading and understanding a question of logical reasoning
}

\section{Francine Baranoski \\ Pereira $^{1}$ \\ orcid.org/0000-0002-8747-7244 \\ francine.baranoski@hotmail.com}

\section{Ângela Inês Klein ${ }^{2}$}

orcid.org/0000-0001-6230-7938

angela.ines.klein@hotmail.com

\section{Ana Lúcia Pereira ${ }^{1}$}

orcid.org/0000-0003-0970-260X anabaccon@uepg.br

Recebido em: $14 / 5 / 2020$ Aprovado em: 22/9/2020 Publicado em: 10/08/2021

\section{(c) (1)}

Artigo está licenciado sob forma de uma licença Creative Commons Atribuicãa 4.0 Internacional.
Resumo: Este artigo apresenta resultados de uma pesquisa, que objetiva investigar o comportamento ocular, através da análise dos mapas de opacidade. número e duração média das fixações e tempo de resolução, a fim de verificar a leitura, a compreensão e a resolução de uma questão de análise de um diagrama, comparando os escores dos que acertaram com os que erraram. Participaram desta pesquisa 11 pessoas de diferentes idades e niveis de estudo: alunos do Ensino Médio, mestrandos, doutorandos e professores doutores das áreas de Ensino e Aprendizagem, Educação e Matemática. Os dados foram coletados no Laboratório de Processamento Visual da Universidade Tecnológica Federal do Paraná, com um rastreador ocular de $500 \mathrm{~Hz}$, que permitiu acompanhar os movimentos oculares durante a leitura, compreensão e resolução.

Palavras-chave: Comportamento ocular. Leitura. Compreensão leitora.

Abstract: This paper presents the results of a research that aims to investigate eye behavior through the analysis of opacity maps, number and average duration of fixations and resolution time, in order to verify the reading, comprehension and resolution of a question of analysis of a diagram, comparing the scores of those who got it right with those who got it wrong. Eleven people of different ages and levels of study participated in this research: high school students, master's students, doctoral students and PhD teachers in the areas of Teaching and Learning. Education and Mathematics. Data were collected at the Visual Processing Laboratory of the Federal Technological University of Paraná, with an eye tracker of $500 \mathrm{~Hz}$, which allowed to follow the eye movements during reading, comprehension and resolution.

Keywords: Eye behavior. Reading. Reading comprehension.

\section{Introdução}

Ler é um processo que exige intensa atividade cognitiva. Para ler e compreender um texto, o sujeito necessita acessar seus conhecimentos e ajustar as informações fonológicas, sintáticas, semânticas e pragmáticas obtidas durante a leitura. Este processo de leitura e compreensão do texto algumas vezes não ocorre de maneira linear, resultando em uma dificuldade de entendimento por parte do leitor (MAIA, 2019).

Estudos aplicados com o rastreador ocular apontam uma nova possibilidade de análise e compreensão destas dificuldades, pois segundo Carpenter, Nagell e Tomasello (1998, p. 15) ao estudar os movimentos oculares, parte-se da suposição "strong eye-mind", que revela que a visualização do sujeito indica seu pensamento real nos processos cognitivos. 
Dessa forma, as gravações desses movimentos demonstram um desenho dinâmico da atenção do sujeito em um determinado campo visual.

Há amplas possibilidades de investigação com o uso do rastreador ocular em pesquisas sobre: movimentos oculares, percepção visual, processamento cognitivo, métodos de resolução de problemas e processos de raciocínio. Para os autores, as pesquisas de rastreamento ocular permitem uma compreensão mais profunda do desenvolvimento conceitual e de muitos problemas cognitivos e aspectos comportamentais em humanos (LAl et al., 2013).

Para Rayner (1998) os dados coletados sobre as direções e o tempo do escaneamento visual de uma determinada área permitem caracterizar com precisão a atividade visual, a fim de indicar como são processados uma imagem e um código de texto.

Assim, pode-se afirmar que utilizar o rastreamento ocular como técnica de pesquisa permite um exame mais profundo dos movimentos oculares nos processos de leitura e compreensão de textos de diversas áreas do conhecimento (MAIA, 2019).

Estudos utilizando rastreamento ocular para compreensão da leitura na Matemática em resolução de problemas, raciocinio lógico e aritmética são em sua maioria internacionais. Os encontrados e que envolvem esta técnica utilizam grupos de estudantes proficientes e menos proficientes em Leitura com desempenhos distintos em Matemática e centram sua análise no número de fixações, tempo e velocidade de leitura durante a resolução dos problemas (SAJKA; ROSIEK, 2015; SCHNEIDER et al., 2012).

Cabe ressaltar, que dentre os estudos realizados sobre movimentos oculares e questões de raciocínio lógico, a pesquisa polonesa intitulada "The eye-tracking research method in the process of solving mathematical tasks requiring drawing analysis", da revista Didactics of Mathematics $n^{\circ}$ 11 (ROŻEK et al., 2014), inspirou e norteou este estudo. Ela foi realizada com 99 participantes, utilizando a técnica de rastreamento ocular com o equipamento modelo iView X Hi-Speed 1250 , enquanto o sujeito resolvia alguns testes de ma- temática, porém o artigo apresentou e analisou os dados de apenas uma questão de raciocinio lógico. O objetivo era determinar o perfil dos métodos de solução de tarefas, através dos mapas de calor com base no número e duração média das fixações e tempo de resolução da questão. Os participantes precisaram analisar três pirâmides de esferas, em múltipla escolha, contendo a pergunta: "Com quantos círculos a sexta pirâmide será construída?".

Assim, houve o interesse de realizar um estudo brasileiro sobre movimentos oculares e situações problema com base nela. O presente estudo apresentará os resultados da pesquisa realizada com 11 participantes de diferentes idades e níveis de conhecimento, utilizando o rastreador ocular de $500 \mathrm{~Hz}$ na leitura, compreensão e resolução de uma questão de raciocinio lógico, que foi uma das 6 questões realizadas pelos participantes. Objetivou-se investigar o comportamento ocular, através da análise dos mapas de opacidade, número e duração média das fixações nas áreas de interesse e tempo de resolução, a fim de verificar a leitura, a compreensão e a resolução de uma questão de análise de um diagrama, comparando os escores dos que acertaram com os que erraram a questão.

Na próxima seção, serão apresentados estudos sobre o processamento da leitura, os movimentos oculares e as medidas do rastreador ocular. Após, será feita a descrição e aplicação do instrumento, a análise e discussão dos dados.

\section{Processamento da leitura e movimentos oculares}

A leitura não é um processo linear, os movimentos oculares variam entre fixações e sacadas regressivas ou progressivas. As fixações ocorrem sobre algumas palavras do texto, podendo ou não serem fixadas mais de uma vez. Já as palavras curtas, geralmente não são fixadas. De alguma forma, todas recebem algum tipo de processamento visual, ainda que nem todas sejam fixadas (RAYNER, 1998).

Os movimentos dos olhos ocorrem da esquerda para a direita na leitura de línguas ocidentais, no entanto, há movimentos observados da direita 
para a esquerda, as chamadas sacadas regressivas, de acordo com Rayner (1998). Estas sacadas servem para verificar novamente a palavra, portanto, são direcionadas para a área que precisa ser processada novamente. Macedo et al. (2007. p. 280) dizem que provavelmente regressões ocorrem de 10 a $15 \%$ de vezes na leitura e servem como uma forma de conferir se uma palavra foi pulada ou se não foi compreendida. Elas podem ser analisadas em função do seu comprimento, a duração, a localização e a direção do movimento.

As sacadas progressivas são caracterizadas pelos saltos que o olho faz de uma fixação até a outra fixação, de modo que o processamento da informação é realizado nos seus intervalos. Durante a leitura, as sacadas apresentam comprimento médio de 7 a 9 letras, mas podem variar de 1 até 18 letras de acordo com Rayner (1998, p. 380).

O processamento de leitura em leitores proficientes se inicia na primeira metade da palavra, assim, se ela for realizada com sucesso, o olho passa para a próxima; caso haja insucesso, ocorre uma segunda e mais longa fixação próxima ao final da palavra (RAYNER, 1998). Leitores proficientes tendem a aumentar a velocidade da leitura à medida que a amplitude da sacada aumenta, quanto maior a familiaridade com a palavra, maior a previsibilidade contextual, que repercute na diminuição no número de fixações e em sua duração; já em leitores não-proficientes, essa capacidade encontra-se limitada em palavras com mais de cinco letras (RAYNER, 1998).

De acordo com Rayner (1998) as fixações têm duração média de 250 milésimos de segundo e dificilmente ocorrem mais de uma vez em palavras curtas (duas ou 3 letras). Em contrapartida, ocorre com mais frequência, em palavras longas. O local, o número e o tempo delas podem variar, sendo esses dados vitais para análise dos processos cognitivos envolvidos na leitura de um texto.

A fixação é capturada na fóvea, que corresponde ao polegar à distância do braço. Para Findlay e Walker (2012) ao investigar o campo visual da fóvea, constata-se que as fixações representam o foco da atenção visual. Deste modo, elas retratam a atenção, enquanto a sua duração revela as possiveis dificuldades de processamento.

Diante das pesquisas apresentadas, verifica-se que há correlação entre o comportamento ocular e a habilidade em leitura.

\section{Metodologia}

Para viabilização desta pesquisa, a proposta foi submetida e aprovada pelo comitê de ética da Plataforma Brasil sob parecer n 3.652.707, CAAE 21584419.3.0000.0105. Trata-se do projeto piloto da tese intitulada: "Análise da compreensão leitora de textos narrativo, expositivo e problemas matemáticos: um estudo com rastreamento ocular", que está em construção.

Os dados foram coletados no Laboratório de Processamento Visual da Universidade Tecnológica Federal do Paraná - Campus Ponta Grossa (UTFPR), com 11 participantes de diferentes faixas etárias e níveis de conhecimento, sendo 4 alunos do Ensino Médio ( $1^{\circ}$ e $2^{\circ}$ anos) de colégios particulares, 3 mestrandos da área de Ensino e Aprendizagem, Educação e Matemática da Universidade Estadual de Ponta Grossa (UEPG), 2 professores doutorandos em Educação e Engenharia na Universidade Tecnológica Federal do Paraná - Campus Ponta Grossa (UTFPR), 2 professores doutores em Matemática atuantes na Universidade Tecnológica Federal do Paraná - Campus Ponta Grossa (UTFPR).

A coleta de dados foi realizada nos meses de outubro, novembro e dezembro de 2018. Foram considerados para análise os dados de 9 participantes, destes: 3 alunos, 3 mestrandos, 1 doutorando e 2 professores. Os dados de 2 participantes foram desconsiderados, devido a dificuldades na calibração e movimento excessivo durante o experimento.

\section{Instrumento}

Para o registro dos movimentos oculares foi utilizado o Rastreador Ocular RED 500, do fabricante alemão SMI (Senso Motoric Instruments), que se define como um equipamento monocular que registra o movimento, a posição e a duração do olhar. O rastreador ocular estacionário com resolução espacial de $0.03^{\circ}$ emite uma fonte de 
luz infravermelha que mede o tamanho e a posição da pupila e a reflexão da córnea do sujeito, fornecendo uma amostra a cada 2ms ( $500 \mathrm{~Hz})$, sendo um rastreador ocular rápido.

Este rastreador está composto de três softwares: iView X, Be Gaze e Experiment Center e possui sensor de alta resolução que permite a movimentação da cabeça de $20 \mathrm{~cm}$ na vertical e $40 \mathrm{~cm}$ na horizontal. É necessário o sujeito tomar uma distância de 60 a $80 \mathrm{~cm}$ do monitor de 22 polegadas com 9 pontos de calibragem, para que os dados coletados sejam fidedignos.

\section{A capacidade de medição do rastreador ocular RED 500}

Para analisar os dados dos movimentos oculares, pode-se optar por uma análise qualitativa, ou seja, através de mapas de estímulo: mapa de calor (heat map); mapa de opacidade (opacity gaze map) e mapa de traçado de olhares (gaze plot), que serão apresentados a seguir, e análise quantitativa, que são os dados numéricos.

Ao programar o experimento, o pesquisador pode realizar a definição das áreas de interesse (areas of interest - AOI), que consiste em definir as regiões relevantes do texto e/ou da imagem, dentro das quais podem ser obtidos dados detalhados da medição. Na Figura 1, são apresentadas as áreas de interesse desta pesquisa: a palavra sexta que norteou este estudo, a imagem das três escadas e a alternativa correta que responde à questão: "Com quantos quadrados a sexta escada será construida? Resposta: $\underline{\text { C) } 21 .}$

Figura 1 - Áreas de interesse

\section{Sequência em escada}

Ana está desenhando uma escada seguindo uma

sequência. Com quantos quadrados a ssextáa escada

será construída?

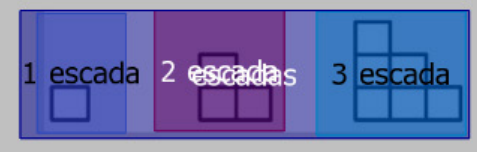
A) 10
B) .28
XalternativasX
D) 36

Fonte: Elaboração própria (2018).

O mapa de traçado de olhares (gaze plot) na Figura 2, mostra quais elementos do texto e da imagem foram observados pelo participante. Sacadas são vistas como linhas contínuas, enquanto as fixações como circulos de diferentes diâmetros. Quanto maior o diâmetro, maior o tempo de fixação sob determinada silaba. Os números sob os círculos e a sua interligação pelas linhas representam a ordem em que cada elemento foi visualizado. Estas representações gráficas, segundo Rayner (1998) ajudam a saber em quais elementos o participante manteve os olhos, quais ganharam mais tempo de fixação e se houve revisitas em alguns deles. 
Figura 2 - Mapa de traçado de olhares

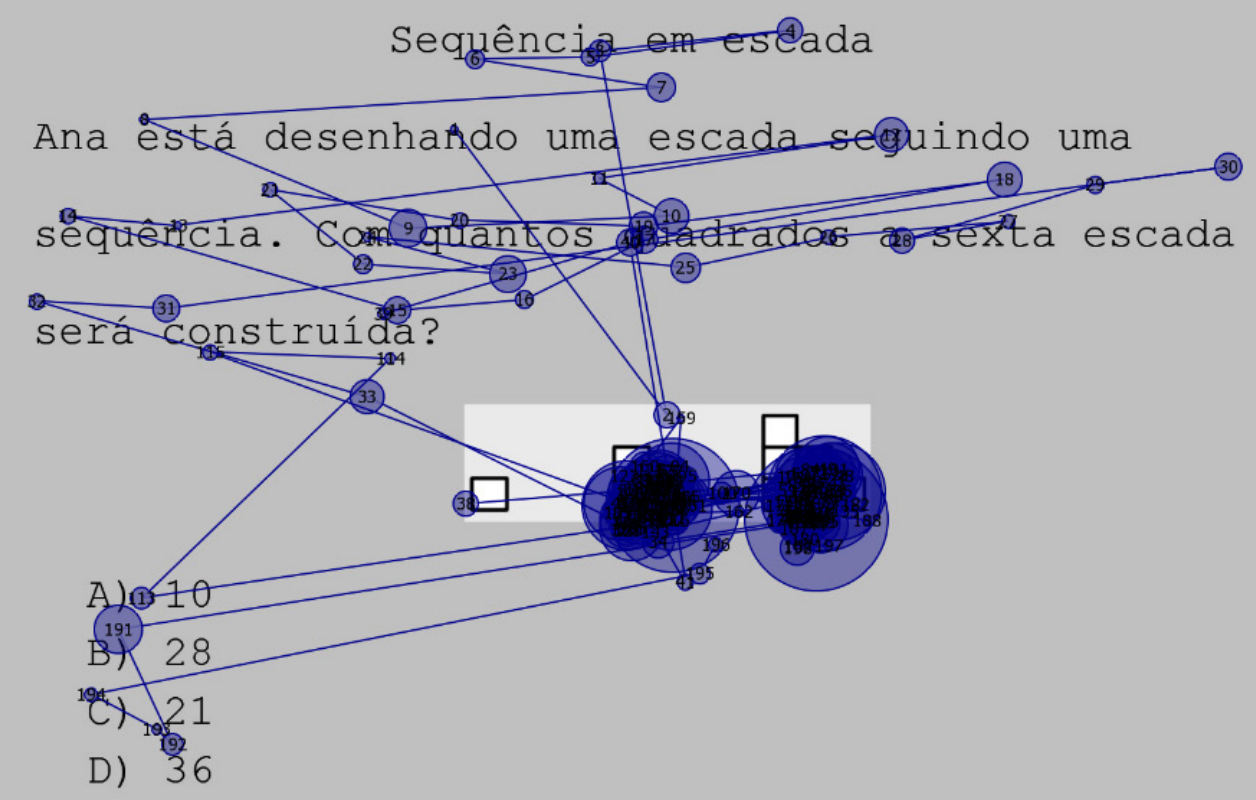

Fonte: Elaboração própria (2018).

Os mapas de calor (heat map) representam o foco de atenção que determinada área recebeu pelo participante. Conforme a Figura 3, a área que recebeu mais atenção está em vermelho e as que estão em verde receberam menor atenção. Assim, os mapas de calor apresentam de maneira gradual (vermelho, amarelo, verde e azul) a área focada com maior ou menor atenção pelo participante.

Figura 3 - Mapa de calor

\section{Sequência em escada}

Ana está desenhando uma escada seguindo uma sequência. Com quantos quadrados a sexta escada será construída?
A) 10
B) 28
C) 21
D) 36

Fonte: Elaboração própria (2018). 
Os mapas de opacidade (opacity gaze map) mostram graficamente o foco de atenção a determinados elementos do texto e imagem. É possivel notar que as zonas em branco (Figura 4) são as que tiveram maior atenção do participante.

Figura 4 - Mapa de opacidade

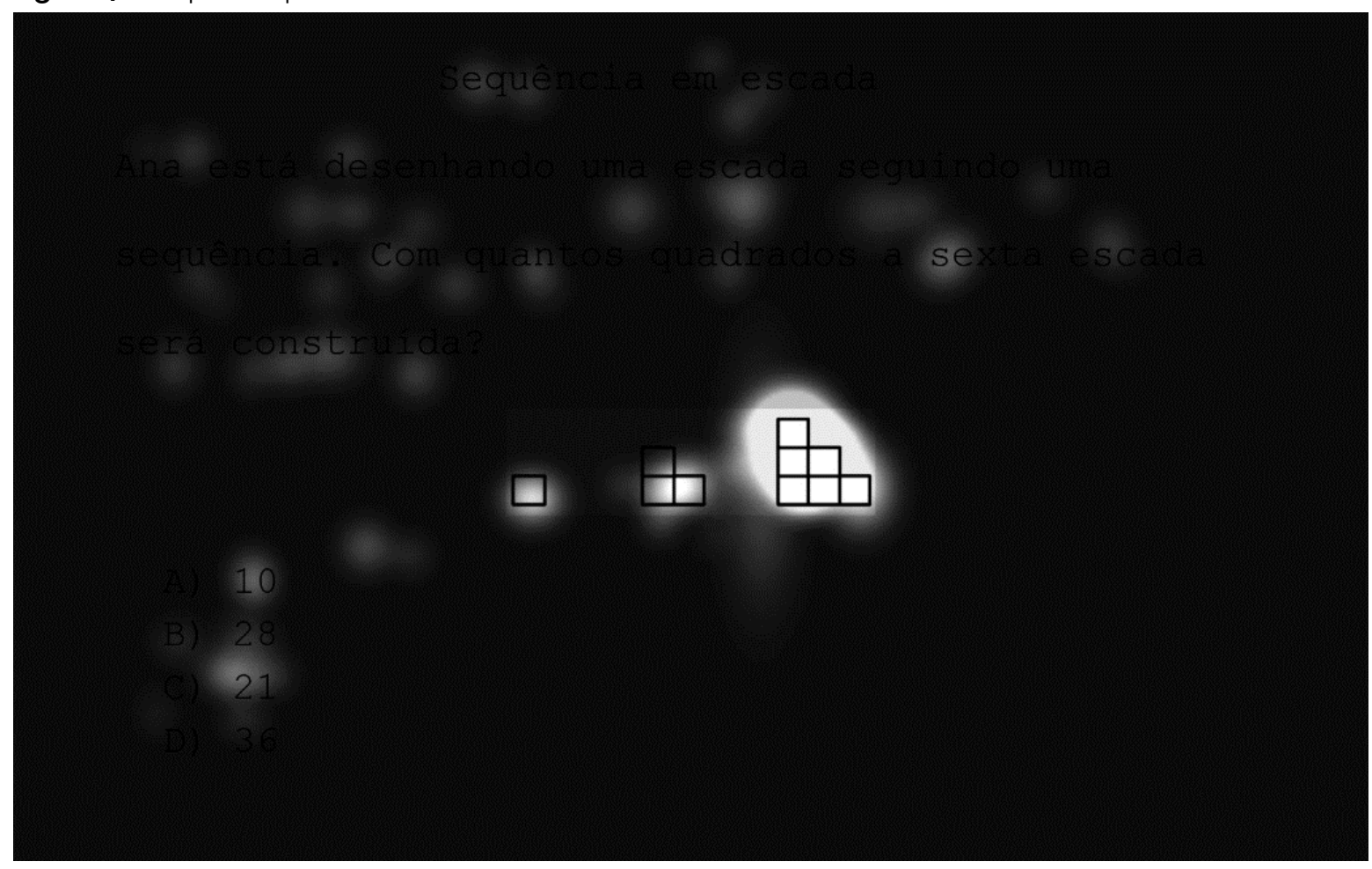

Fonte: Elaboração própria (2018).

\section{Descrição do instrumento}

Os participantes da pesquisa leram e resolveram 6 questões, ou seja, situações problema. Elas fazem parte dos itens liberados da Prova Pisa (INEP, 2012). As questões foram modificadas, respeitando as limitações de tamanho da tela do monitor no qual o rastreador ocular está acoplado, sendo três questões de múltipla escolha e três questões abertas.

Este artigo analisa uma das questões, a chamada "Sequência em escada", classificada como uma questão de raciocínio lógico, que foi inspirada na questão do estudo polonês já mencionado na introdução. Na prova PISA esta questão era aberta, tinha outro sujeito da oração e perguntava quantos quadrados a quarta escada teria, diferentemente da apresentada a seguir, que possui como sujeito a Ana, é uma questão de múltipla escolha e pergunta a respeito de quantos quadrados a sexta escada teria (Figura 5):
Figura 5 - Sequência em escada

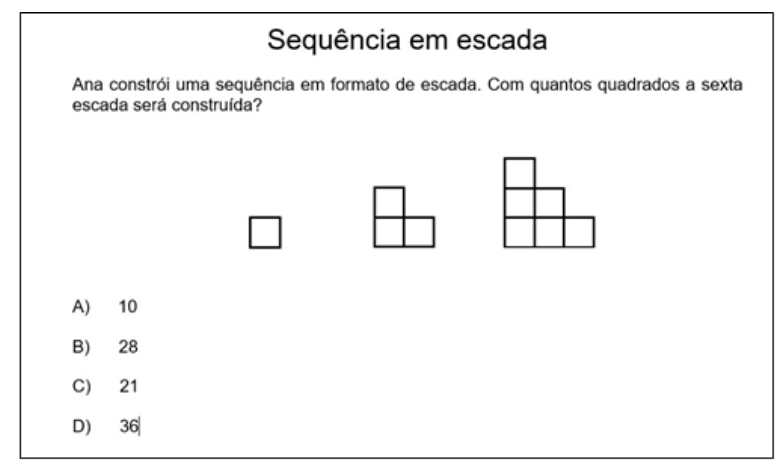

Fonte: Adaptado de INEP/PISA (2012).

\section{Aplicação do instrumento}

Aos participantes da pesquisa foram disponibilizados no máximo 2 minutos para que lessem a questão no monitor e a resolvessem mentalmente. Depois disso, a tela do monitor ficava cinza, que era o momento em que a pesquisadora anotava a resposta que o participante acreditava ser a correta 
e uma breve descrição oral do seu raciocínio para chegar àquela resposta, ou seja, um protocolo oral. Após a leitura e resolução da questão no equipamento, os participantes resolveram a mesma questão no papel, com o tempo cronometrado e tendo, no máximo, 2 minutos, podendo novamente relatar como chegaram à resposta. Os dados de tempo de resolução e o protocolo oral da resolução foram anotados no verso da questão.

\section{Levantamento e tabulação dos dados}

Partiu-se de uma abordagem qualitativa para a análise das fixações através dos mapas de opacidade, os quais são construidos com base no número e duração das fixações por meio de um arranjo térmico que reflete a atenção visual do participante. Deste modo, a área mais branca é aquela em que o participante realizou um número e uma duração mais alta de fixações, ou seja, representa o local que recebeu mais atenção. Estes mapas são gerados pelo software BeGaze, do fabricante SMI.

Considerou-se a palavra sexta como importan- te para análise, a exemplo do estudo de Rożek et al (2014) citado na introdução, cujo objetivo era determinar o perfil dos métodos de solução da questão, através dos mapas de calor. A análise dos resultados da pesquisa polonesa concluiu que não somente o número de fixações nas áreas de interesse e tempo de resolução foram importantes para determinar o acerto da questão, mas principalmente as revisitas na palavra "sexta".

Deste modo, a presente análise considerou o tempo médio das fixações na palavra sexta em segundos, número de fixações na palavra e o número de revisitas nela. Também foi observado o acerto e o erro da questão, além do tempo de resolução do problema em segundos.

Optou-se por nomear os participantes da pesquisa como: A1, A2, A3 para os 3 alunos do Ensino Médio, M1, M2, M3 para os 3 mestrandos da área de Ensino e Aprendizagem, Educação e Matemática, D1 para o doutorando em Educação e P1, P2 para os 2 professores doutores em Matemática, como está disposto na tabela 1.

TABELA 1 - Dados referente à questão "Sequência em escada"

\begin{tabular}{cccccc}
\hline $\begin{array}{c}\text { Participantes } \\
\text { da pesquisa }\end{array}$ & $\begin{array}{c}\text { Tempo médio } \\
\text { de resolução } \\
\text { da questão } \\
\text { (segundos) }\end{array}$ & $\begin{array}{c}\text { Média do tempo } \\
\text { de fixações na } \\
\text { palavra sexta } \\
\text { (segundos) }\end{array}$ & $\begin{array}{c}\text { Número de } \\
\text { fixações da } \\
\text { palavra sexta }\end{array}$ & $\begin{array}{c}\text { Número de } \\
\text { revisitas na } \\
\text { palavra sexta }\end{array}$ & $\begin{array}{c}\text { Acerto (A) } \\
\text { Erro (E) }\end{array}$ \\
\hline A1 & 120 & 0,15 & 6.0 & 4.0 & E \\
A2 & 36 & 0,18 & 2.0 & 1.0 & A \\
A3 & 81 & 0,27 & 5.0 & 2.0 & $\mathrm{~A}$ \\
D1 & 100 & 0,11 & 4.0 & 6.0 & $\mathrm{~A}$ \\
M1 & 117 & 0,09 & 8.0 & 2.0 & $\mathrm{E}$ \\
M2 & 92 & 0,09 & 3.0 & 1.0 & $\mathrm{~A}$ \\
M3 & 46 & 0,14 & 1.0 & 1.0 & $\mathrm{~A}$ \\
P1 & 65 & 0,1 & 1.0 & 0.0 & $\mathrm{E}$ \\
\hline
\end{tabular}

Fonte: Elaboração própria (2018).

Na próxima seção, serão discutidos os mapas de opacidade e os dados quantitativos apresentados na Tabela 1.

\section{Análise e discussão dos dados}

De acordo com os dados dispostos na Tabela 1, é possivel perceber que os participantes que erraram a questão necessitaram de tempo maior 
de resolução (120, 117 e 115 segundos) do que os que acertaram (de 36 a 100 segundos).

Com relação à média do tempo de fixação na palavra sexta, não se pode afirmar que os participantes que mais fixaram na palavra erraram ou acertaram a questão, pois o participante A3 acertou com média de fixação de 0,27 segundos, já o participante P2 errou com média de fixação de 0,26 segundos.

Sobre o número de fixações na palavra sexta, pode-se notar que os dados dos participantes A1 e M1 (6.0 e 8.0) revelam que houve dificuldade no processamento da palavra devido à maior quantidade de fixações na área de interesse. Segundo McConkie e Rayner (1975), o número de fixações aumenta quando o leitor apresenta dificuldades na fluência da leitura, o que corrobora os dados encontrados e discutidos.

Igualmente interessantes são os dados com relação ao número de revisitas na palavra pré-determinada: os participantes que erraram a questão tiveram 4.0, 6.0 e 0.0 revisitas na área de interesse. Isto revela que houve padrões opostos de comportamento ocular, ou seja, parece que excesso ou falta de revisitas implicam em insucesso na resolução da questão.

Figura 6 - Mapa de opacidade - erro da questão
Para Murray e Kennedy (1998), as sacadas regressivas ou revisitas são para refixar a palavra, objetivando uma nova averiguação. Os autores diferem bons de maus leitores, afirmando que quanto mais sacadas regressivas, maior dificuldade de processamento da leitura, já bons leitores apresentam menor número de sacadas regressivas. Vale lembrar que, através das sacadas regressivas, é que são geradas as revisitas.

A porcentagem de participantes que acertaram a questão ficou em $67 \%$ e de participantes que erraram em 33\%. Os que erraram estão caracterizados por: 1) necessitaram de mais tempo para resolução; 2) utilizaram o máximo tempo para a resolução, que foram 2 minutos; 3) tiveram o maior número de fixações; 4) tiveram um comportamento de extremos quanto ao número de revisitas, ou seja, fizeram grande número de revisitas ou nenhuma revisita na palavra sexta.

Na tentativa de ilustrar melhor o comportamento ocular, diferenciando quem acertou daqueles que erraram a questão, serão apresentados dois mapas de opacidade, os quais estão baseados no número e duração das fixações (Figuras 6 e 7).

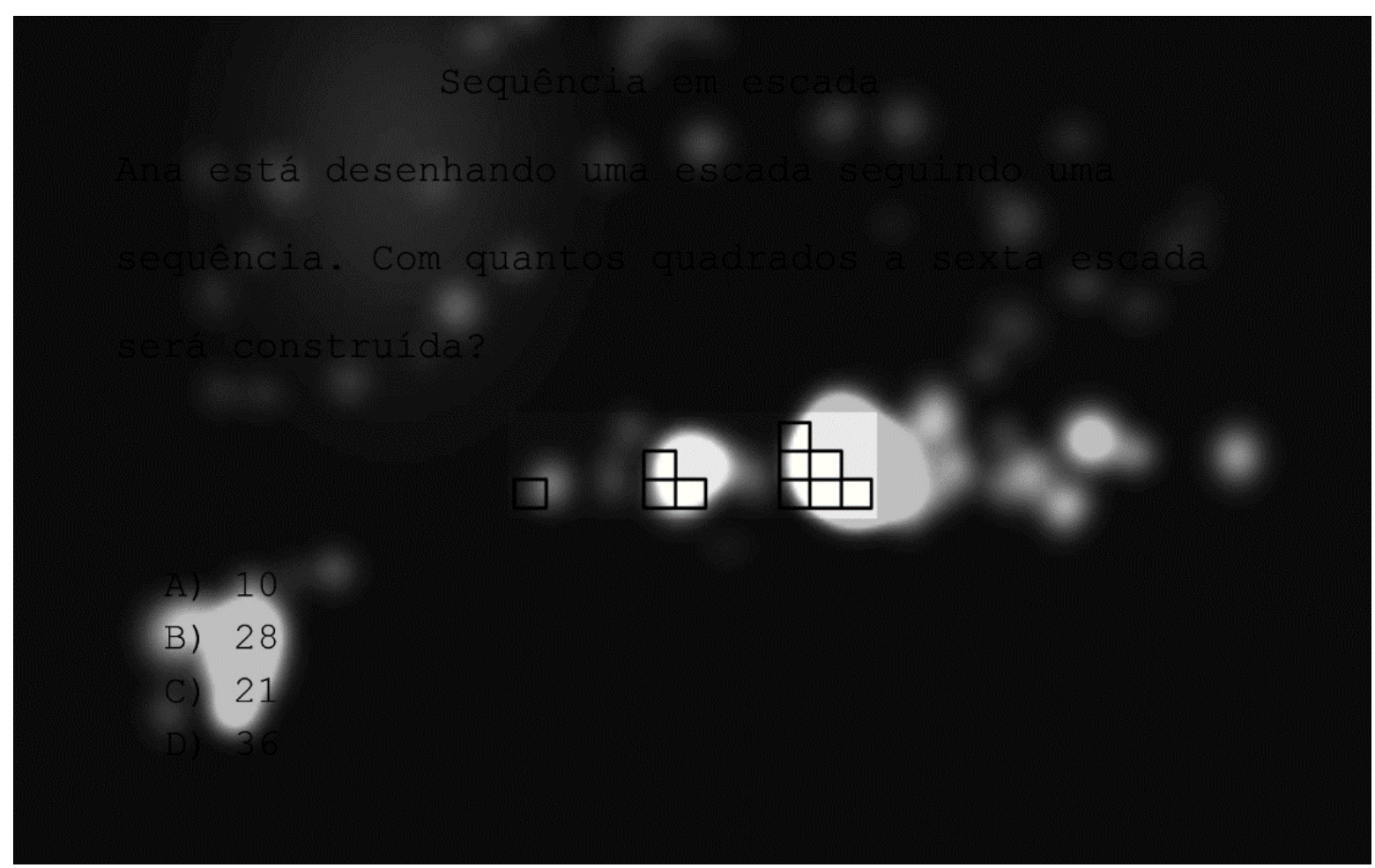

Fonte: Elaboração própria (2018). 
O mapa da Figura 6 representa o comportamento ocular de um participante que errou a questão. As áreas em branco são as que receberam mais atenção, percebe-se que o participante deu pouca atenção ao enunciado da situação problema e partiu diretamente para a análise da imagem na tentativa de localizar a resposta. Sua resposta errônea talvez seja devido à falta de análise mais apurada dos dados dispostos no enunciado (Figura 6).

Figura 7 - Mapa de opacidade - acerto da questão

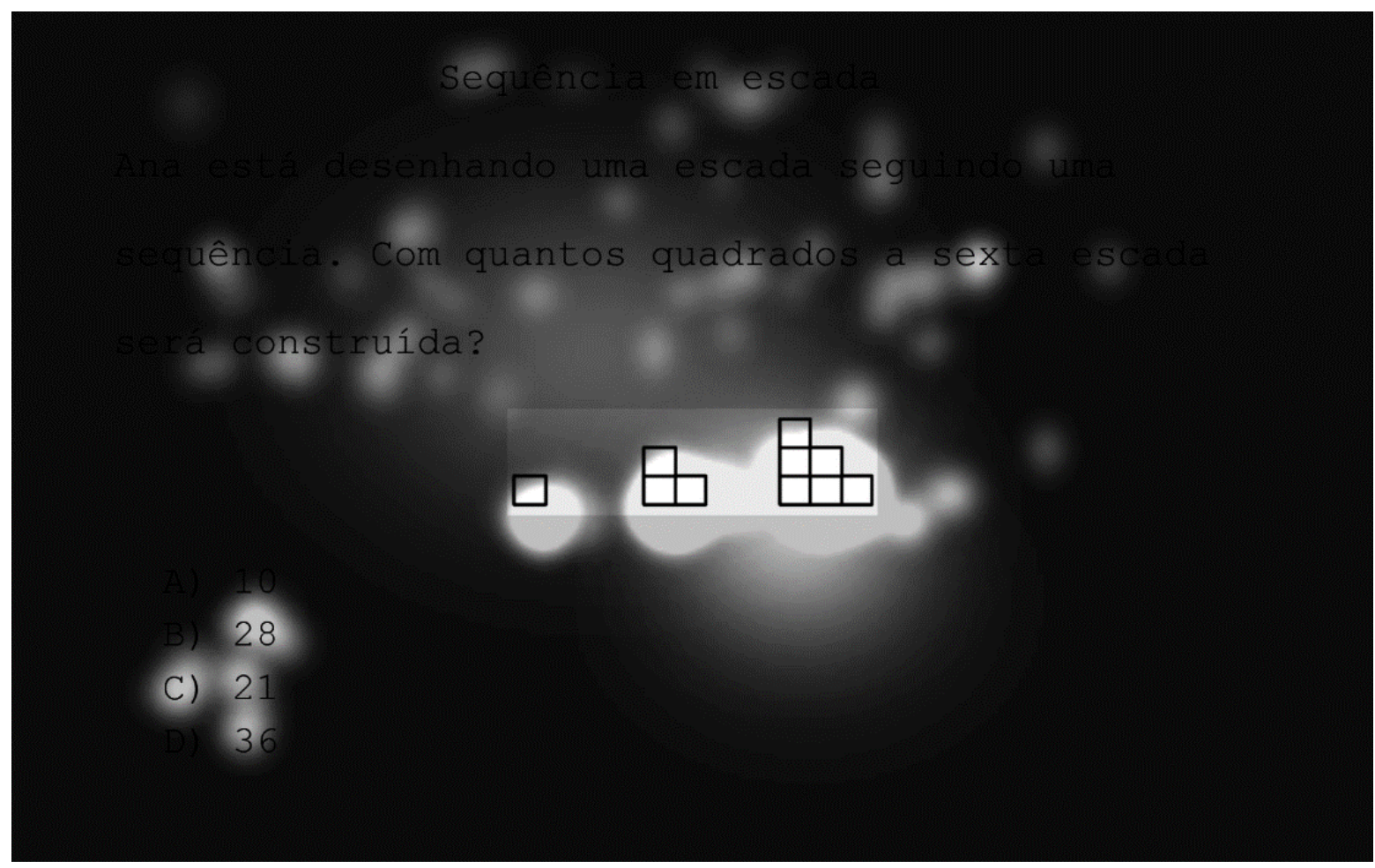

Fonte: Elaboração própria (2018).

Este mapa de opacidade (Figura 7) apresenta o foco de atenção de um participante que acertou a questão. Esta figura difere da anterior, pois é perceptivel que o participante está mais atento aos dados da situação problema, inclusive da área de interesse (sexta). Nota-se que é realizada uma leitura mais detalhada, resultando na escolha da resposta correta.

As fixações presentes nos mapas apresentados indicam a tomada de decisão do leitor, ao optar em dar atenção a determinado local e desconsiderar outras áreas. De acordo com essas pistas, o pesquisador infere o processamento da informação, segundo Rayner (1998). Como foi exposto tanto através dos mapas de opacidade quanto dos dados numéricos, o comportamento ocular de quem acertou e de quem errou a questão é bastante distinto, mesmo com uma amostra tão pequena.

Os resultados da pesquisa polonesa mostram que $15,2 \%$ dos participantes que acertaram a questão usaram o tempo máximo de resolução permitido, no caso 60 segundos. O tempo abaixo de 40 segundos levou os participantes ao erro, diferentemente dos dados apresentados e discutidos anteriormente que mostram os participantes que acertaram a questão com menor tempo de resolução (de 36 a 100 segundos) e os participantes que erraram usaram mais tempo (120, 117 e 115 segundos).

Outro resultado divergente foi relacionado ao número de revisitas na palavra sexta. No estudo polonês, foi concluido que quem omitiu a leitura da palavra sexta, embora tenha sido destacado pelo uso de negrito, errou a questão. Para eles, a palavra destacada continha uma condição textual determinante na resolução da tarefa, que, quando foi levada em conta, determinou a resposta correta.

No presente estudo, os participantes que erra- 
ram a questão, tiveram 4.0, 6.0 e 0.0 revisitas na área de interesse, o que mostra a existência de padrões de comportamento ocular opostos, ou seja, tanto ausência de revisitas quanto excesso resultaram no insucesso da resolução da questão.

Assim, constata-se que o estudo polonês e o atual apresentaram resultados distintos quanto ao comportamento ocular durante a leitura e compreensão de uma questão de raciocínio lógico. Esse resultado talvez se justifique pela quantidade de participantes: enquanto desta pesquisa foram considerados os dados de 9 pessoas, o polonês contou com 99 participantes. Portanto, para conclusões definitivas, seria necessário coleta de dados com mais participantes brasileiros.

\section{Considerações finais}

A investigação do processamento da leitura e do processamento cognitivo, através de registro e análise dos movimentos oculares, caracteriza-se como uma metodologia bastante inovadora e norteadora para compreender as dificuldades de leitores, durante o processamento da informação linguística, ainda pouco usada no Brasil. Esta restrição ocorre, porque além de ser um equipamento de alto valor, exige ser instalado em um local com determinadas adequações, tais como cadeira e mesa com regulagem de altura, suporte de cabeça para evitar movimentos excessivos, sala com isolamento acústico e luminosidade controlável, além de conhecimento específico para operar o equipamento.

Estudos sobre movimentos oculares e processamento da leitura são altamente recomendáveis em diversas áreas do conhecimento, principalmente, na educacional, pois fornecem dados fidedignos do processamento cognitivo pelos movimentos oculares, permitindo real entendimento das dificuldades dos pesquisados. Os resultados podem servir de base para questões que envolvem ensino e aprendizagem, bem como compreender dificuldades em leitura.

Os resultados desta pesquisa indicam que os participantes que erraram a questão necessitaram de tempo superior de resolução, fizeram mais fixações na área de interesse e tiveram um maior número de revisitas ou nenhuma revisita na palavra sexta. Porém, mais estudos e pesquisas são necessários com um maior número de participantes e mais questões de raciocinio lógico, a fim de caracterizar um comportamento ocular típico de quem acerta ou erra questões desse tipo.

\section{Referências}

CARPENTER, Malinda; NAGELL, Katherine; TOMASELLO, Michael. Social cognition, joint attention, and communicative competence from 9 to 15 months of age. NCBI, [S. I.], v. 63, n. 4, p. 176-183, set./dez. 1998. http://doi.org/10.2307/1166214

FINDLAY, John; WALKER, Robin. Human saccadic eye movements. Scholarpedia, [S. I.], v. 7. n. 7. p. 20-37, set./ dez. 2012. http://doi.org/10.4249/scholarpedia.5095

INSTITUTO NACIONAL DE ESTUDOS E PESQUISAS EDUCACIONAIS "ANISIO TEIXEIRA" (INEP). Itens liberados de Matemática. Brasilia: OCDE; PISA; INEP, 2012. Disponivel em: https://download.inep.gov.br/ acoes_internacionais/pisa/itens/2012/pisa_2012_matematica_itens_liberados.pdf. Acesso em: 10 nov. 2019.

LAl, Meng et al. A review using eye-tracking technology in exploring learning. Educational Research Review, [S. I.], v. 10, n. 2, p. 90-115, dez. 2013. http://doi.org/10.1016/j. edurev.2013.10.001

MACEDO, Eliseu Coutinho et al. Processos perceptuais e cognitivos na leitura de palavras: propriedades dos movimentos oculares. Psicologia Escolar e Educacional, [S. I.], v. 11, n. 2, p. 275-283, dez. 2007. http://doi. org/10.1590/S1413-85572007000200007

MAIA, Marcus. Computação Estrutural e de Conjunto na Leitura de periodos: um estudo de rastreamento ocular. In: MAIA, Marcus (org.). Psicolinguística e Educação. Campinas: Mercado de Letras, 2019. p. 103-132.

MCCONKIE, George; RAYNER, Keith. The span of the effective stimulus during a fixation in reading. Perception \& Psychophysics, [S. I.], v. 17, n. 1, p. 578-587, nov. 1975. http://doi.org/10.3758/BF03203972

MURRAY, Wayne; KENNEDY, Alan. Spatial coding in the processing of anaphor by good and poor readers: evidence from eye movement analyses. Quarterly Journal of Experimental Psychology, Glasgow, v. 40, n. 1, p. 693-718, nov. 1988. http://doi.org/10.1080/14640748808402294

RAYNER, Keith. Eye movements in reading and information processing: 20 years of research. Psychological bulletin, [S. I.], v. 124, n. 3, p. 372- 392, maio 1998. http:// doi.org/10.1037/0033-2909.124.3.372

ROŻEK, Bożena et al. The eye-tracking research method in the process of solving mathematical tasks requiring drawing analysis. Didactics of Mathematics, [S. I.], v. 15, n. 11, p. 43-58, maio 2014. http://doi.org/10.15611/ dm.2014.11.04 
SAJKA, Miroslawa; ROSIEK, Roman. Solving a problem by students with different mathematical abilities: a comparative study using eye-tracking. In: CONGRESS OF THE EUROPEAN SOCIETY FOR RESEARCH IN MATHEMATICS EDUCATION, 9., 2015, Prague. Proceedings [...]. Prague, Czech Republic: Faculty of Education; Charles University in Prague, fev. 2015. p. 1752-1758. Disponivel em: https://hal.archives-ouvertes.fr/hal-01288030/ document. Acesso em: 18 set. 2020.

SCHNEIDER, Elisa et al. Eye gaze reveals a fast, parallel extraction of the syntax of arithmetic formulas. Cognition, [S. I.], v. 125, n. 3. p. 475-490, dez. 2012. https://doi. org/10.1016/j.cognition.2012.06.015

\section{Francine Baranoski Pereira}

Mestre em Ensino de Ciência e Tecnologia pela Universidade Tecnológica Federal do Paraná (UTFPR), em Ponta Grossa, PR, Brasil; graduada em Licenciatura em Letras Português Espanhol pela Universidade Estadual de Ponta Grossa (UEPG), em Ponta Grossa, PR, Brasil. Especialista em Lingua Portuguesa e Literatura pelo ESAP, em Ponta Grossa, PR, Brasil; doutoranda em Educação pela UEPG; bolsista CAPES; professora tutora do Curso de Letras da UAB/UEPG, em Ponta Grossa, PR, Brasil. Integrante do Grupo de Pesquisa "Linguagem, Ensino e Cognição", vinculado ao Programa de Mestrado de Ensino de Ciência e Tecnologia, da Universidade Tecnológica Federal do Paraná, Campus de Ponta Grossa, PR, Brasil; e do Grupo de Pesquisa: "Políticas Educacionais e Formação de Professores", da UEPG.

\begin{abstract}
Ângela Inês Klein
Doutora e mestre em Linguística pela Pontificia Universidade Católica do Rio Grande do Sul (PUCRS), em Porto Alegre, RS, Brasil, com estágio de doutoramento no Programme for Experimental and Clinical Ling pela Universidade de Potsdam, da Alemanha. Graduada em Letras pela Universidade do Vale do Rio dos Sinos (UNISINOS), São Leopoldo, RS, Brasil; pesquisadora e professora da Universidade Federal de Pelotas (UFPel), em Pelotas, RS, Brasil, tendo fundado o Laboratório de Processamento Visual durante o tempo em que atuou na Universidade Tecnológica Federal do Paraná.
\end{abstract}

\section{Ana Lúcia Pereira}

Doutora e mestre em Ensino de Ciências e Educação Matemática pela Universidade Estadual de Londrina (UEL), em Londrina, PR, Brasil; graduada em Ciências/Matemática na Universidade do Norte Pioneiro (UENP); professora do Departamento de Matemática e Estatística da Universidade Estadual de Ponta Grossa (UEPG), em Ponta Grossa, PR, Brasil, e dos Programas de Pós-Graduação em Educação e Ensino de Ciências e Educação Matemática na UEPG. É membro do Banco de Avaliadores do Sistema Nacional de Avaliação da Educação Superior-BASis-INEP/MEC e bolsista de produtividade da Fundação Araucária-Paraná.

\section{Endereço para correspondência}

Francine Baranoski Pereira

Rua Gaton Busquet, 206, Residencial Poente, casa 32

Ronda, 84050-370

Ponta Grossa, PR, Brasil 